8 Koller WC, Weiner WJ, Diamond BI, Nausieda PA, Klawans HL. The pharmacological evaluation of pergolide mesylate as a potential anti-parkinson agent. Neuropharmacol 1980;19:831-7.

9 LeWitt PA, Ward CD, Larsen TA, et al. Comparison of pergolide and bromocriptine therapy in Parkinsonism. Neurology 1983;33:1009-14.

10 Leiberman AN, Neophytides A, Leibowitz M, et al. Comparative efficacy of pergolide and bromocriptine in patients with advanced Parkinson's disease. In: Fahn S, Calne DB, Shoulson I, eds. Advances in Neurology 1983;95-108.
11 Hoehn MM, Yahr MD. Parkinsonism: onset, progression, and mortality. Neurology 1967;17: 427-42.

12 Goetz CG, Tanner CM, Glantz RH, Klawans HL. Chronic agonist therapy for Parkinson's disease: a 5-year study of bromocriptine and pergolide. Neurology 1985;35:749-51.

13 Quinn NP, Koller WC, Lang AE, Marsden CD. Painful Parkinson's disease. Lancet 1986;i:1366-9.

14 Nausieda PA, Weiner WJ, Klawans HL. Dystonic foot response of Parkinsonism. Arch Neurol 1980;37:132-6.

\section{The Ramsay Hunt syndrome}

"This syndrome may be divided into three clinical groups: (1) Herpes zoster auricularis, (2) Herpes zoster in any of the zoster zones of the cephalic extremity (herpes auricularis, herpes facialis, and herpes occipito-collaris) with facial palsy, (3) Herpes zoster of the cephalic extremity with facial palsy and auditory symptoms (tinnitus, deafness, vertigo, vomiting, nystagmus and disturbances of equilibrium)".

Hunt J Ramsay. On herpetic inflammations of the geniculate ganglion. A new syndrome and its complications. J Nerv Ment Dis 1907; 34:73-96.

\section{Todd's paralysis}

JB Lyons" states "Todd's right to the eponym 'Todd's Paralysis' is indisputable. Postictal paralysis is described in the Lumleian Lectures for $1849^{2}$ : "A paralytic state remains sometimes after the epileptic convulsion. This is more particularly the case when the convulsion has affected only one side or one limb: that limb or limbs will remain paralytic for some hours, or even days, after the cessation of the paroxysm, but it will ultimately perfectly recover-".

\section{References}

RT ROsS 1 Lyons JB. The Neurology of Robert Bentley Todd in Historical Aspects of the Neurosciences. In: Rose FC, Bynum WF, eds. New York: Raven Press, 1981:145.

2 Todd RB. London Medical Gazette 1849;8:668 